\title{
Small Steps Across the Chasm: Ideas for Embedding a Culture of Open Education in the University Sector
}

\author{
Lisa Harris, Lorraine Warren, Jean Leah, and Melanie Ashleigh \\ University of Southampton
}

\begin{abstract}
The authors critique the commonly accepted notions of "digital native" students and the widening generation gap between them and "technophobic" faculty. Their case studies, from UK higher education, demonstrate that attempts to introduce new models of learning are inhibited by 1) prevailing structure and culture within universities and 2) expectations (or even a stated preference) for traditional delivery and assessment of knowledge by the students themselves. The authors recommend a strategy for more systemic integration of social technologies and new learning styles into the curriculum to help ensure that universities remain relevant and add value to learners and employers in the digital age.
\end{abstract}

Keywords: digital native; technophobic; higher education; social technologies; learning styles 


\section{Small Steps Across the Chasm: Ideas for Embedding a Culture of Open Education in the University Sector}

\section{"If you don't like change, you're going to like irrelevance even less."}

(General Eric Shineski, US Army Chief of Staff)

It is increasingly evident that the "digital divide" between the "haves" and the "have nots" in the developed world is now less about access to the web than it is about understanding how to actively participate in the networked society (Harris \& Rae, 2010). The ability to create and share knowledge, to effectively network and engage with global professional communities, and to stay aware of constantly emerging new knowledge in a particular field of practice, are already essential competencies for a modern professional. But are universities producing graduates who meet these criteria and hence can be considered "fit for purpose" in the modern business world?

In this paper, we will present recommendations for change within higher education to help ensure that universities can remain relevant and add value to learners and employers in the digital age. The following research will critique the commonly accepted notions of "digital native" students and the widening generation gap between them and "technophobic" faculty. In practice, we find that the familiarity with, and acceptance of, social technologies in education varies significantly for both staff and students. Furthermore, the research will draw upon theories of innovation, technological change, recent studies of the role of Web 2.0 technologies in developing a culture of open education, and empirical data to present recommendations for the more systemic integration of social technologies and new learning styles into the curriculum. The two case studies of new initiatives by "early adopter" staff demonstrate that attempts to "cross the chasm" by introducing new models of learning can be inhibited by (a) the prevailing structure and culture within universities and (b) an expectation (and in some cases, a stated preference) for traditional delivery and assessment of knowledge by the students themselves. The result is that the full potential of social technologies to enhance learning is currently not being realized.

Theoretically, this paper is situated in the context of social learning. Social learning is not new; constructivists such as Vygotsky (1962) proposed that children should make sense of their own learning through social interaction in groups, and later Kolb (1984) showed that experiential learning enables students to extract information, reflect upon their experience, and adapt their learning more effectively. Social technologies have the potential to facilitate and showcase experiential learning on a greater scale. Take, for example, the knowledge creation process; a concrete experience where communication is extracted through different technologies and is facilitated using wikis and blogs to draw upon global communities of expertise. Subsequently, students can assess the relative value of diverse sources of information through social bookmarking tools such as Digg or Delicious. This means that learners can develop a sense of the importance of an article or video in terms of the number of viewers who have bookmarked it and the nature and extent of the comments made about it. In this environment, not only does the student grow into a more independent social learner, but also the role of the tutor changes or can even disappear altogether. The magnitude of the changes is such that the classical notion of a geographically situated university, delivering a defined knowledge base to clearly defined cohorts of students is itself under threat. Previously, learning technologies have enriched and extended that business model. However, students could now move from a learning environment controlled by the tutor and the institution, to one where they direct their own learning according to personal interests, find their own information, and create knowledge by engaging in relevant networks of expertise that could be physically located anywhere in the world. 
There is also the possibility that theories of social learning now need to take account of the theory of disruptive innovation that could potentially impact the HE sector in a profound manner. In a recent Demos Report (Bradwell, 2009), the challenges now facing the higher education sector are compared to those which the music industry faced 10 years ago (it is noted the threat was not to music itself, but to the way that traditional business models in the industry worked). Universities need to learn from the 'heads in the sand' approach that was taken by the record companies as new ways of creating, finding and purchasing music became possible, and apply those lessons to education. The research presents some suggestions. But can the reality match this rhetoric in the modern university?

\section{A Brief History}

David (1991) described how in the 19th century the dynamo was developed as a challenger to the established production technology, which was then the steam engine. Although the new technology was clearly superior, productivity benefits were slow to materialise because the system of production continued to operate on the model developed for the steam engine. Parallels can be drawn here with the ways in which new learning technologies are struggling to fulfil their potential when they have to fit - often uneasily - within a traditional university structure and culture which no longer matches today's world, a place where information is abundant and freely shared through global networks with little respect for expertise and established hierarchies. In the business world, there are plenty of recent examples where such a mismatch between a traditional industry and the changing markets it serves leads to irrelevance.

However, the industrial model, built for a very different world, continues to predominate in education. While social learning theorists have had some influence in the last four decades, largely this has taken place within that industrial paradigm, with incremental improvements slowly taking place over time. More recently, however, the widespread availability of networked technologies and easily accessible software platforms has lead some authors to argue that there is the potential for a much more radical structural transformation of the sector, reflecting changes in wider society. Long and Holeton (2009) note that universities were originally designed to reinforce the authority of the teacher transmitting a set body of knowledge, and the authors claim that learning in new media environments requires a rethinking of both education and the studentteacher relationship. "Existing physical structures (classrooms), ageing social structures (standards, tenure and promotion systems), and outdated cognitive structures (information as "things" that must be in physical "places") must all be transformed” (Long \& Holeton, p. 37). This claim is endorsed by George Siemens, interviewed in ELearn magazine (Gualtieri, 2009):

We begin to notice the growing mismatch of education to the societal context in which it exists. How can we reframe education to better serve the ability of individuals to participate in and make sense of tremendous quantities of information? How do we acknowledge and foster expertise in a continual flow of information? Our education system no longer matches the needs of today's society. (p. 1)

Within UK universities, there are many excellent examples of projects that seek to address these questions and challenge traditional structures and mindsets. However, they tend to be rather isolated from the core curriculum, hence, limited in their impact, even within their own departments where traditional models tend to predominate and senior staff is wary of new teaching approaches. As Bradwell (2009) notes, “The next stage of technological investment must be more strategic. The sector currently lacks a coherent narrative of how institutions will 
look in the future and the role of technology in the transition to a wider learning and research culture" (p. 14). Therefore, to maintain relevance and foster enthusiasm for "lifelong learning," thereby producing independent, proactive learners who are able to become productive participants in today's business world, universities should be viewing the curriculum through a more strategic lens - a process which will require systemic change to traditional structures as well as supportive attitudes from both staff and students. The next section reviews some of the ways in which social media may be harnessed to facilitate this process.

\section{Web 2.0 as a Potentially Disruptive Technology in Higher Education}

Christensen, Antony, and Roth's (2004) theory of disruptive technologies helps explain how innovations only gradually permeate through existing systems and processes. By providing value to learners outside of the established academic model, the application of Web 2.0 technologies could be the disruptive influence that is instrumental in moving traditional hierarchical broadcast models of education, structured around a defined body of knowledge, towards a networked approach, which is more adaptive to the needs of learners. According to Long and Holeton (2009):

These individual projects, possible signposts of the revolution, may show the way to replacing the industrial model with a model of inquiry. Unfortunately, they may also go almost unrecognized by the cultures in which they're found, because of a collective inability to achieve a common language with which to describe learning environments and their aspirations. To be transformative, the inquiry model must be embedded in a discourse and culture of inquiry - in language and practice that marry the needs of the twenty-first-century learner to the pedagogies of engagement and that connect those needs to actual learning environments. (p. 1)

We introduced the theory of social learning at the start of this paper. According to Seely Brown and Adler (2008), the most profound impact of the Internet is its ability to support social learning, meaning that our understanding of content is influenced not just by "what" we are learning, but on "how" we are learning. We cite Light's (2001) discovery that one of the strongest determinants of students' success in higher education was their ability to participate in small study groups. These students were more engaged in their studies (than their peers who worked alone), better prepared for class, and learned significantly more. By working in groups, students can clarify areas of uncertainty and, in turn, help their colleagues who may be struggling. Tools such as blogs, wikis, social networks, tagging systems, mashups, and contentsharing sites greatly facilitate such group work through their focus on conversation, participation and action-based learning, while also overcoming geographical boundaries and other barriers to community development. Hence, it could be argued that the possibilities of the Internet, its global character and potential for social learning, alongside ageing models of university provision, may be building up to a tipping point where new business models are needed.

Seely Brown and Adler (2008) call for a new approach to learning that is characterized by "demand-pull” (driven by the particular interests of the learner) rather than the traditional "supply-push" mode of knowledge acquisition (with specific content dictated by the tutor or institution). However, there is danger in assuming that all students are familiar with, and receptive to, innovative approaches to learning. We will demonstrate in the next section and in our case studies that this is not necessarily the case, as some students (and indeed staff) will require significant levels of support and guidance. 
Prensky (2001) argued that this group of digital natives constituted the first generation of students to grow up with the Internet, having spent their entire lives exposed to computers, video games, digital music players, video cams, and mobile phones. A more recent endorsement of this view is provided by extensive research carried out with US teenagers by Tapscott (2008), who noted the need for a greater focus on the development of problem solving skills in a world where information is abundant, rather than on memorizing a contained amount of tutor-directed content. Research conducted by the European Interactive Advertising Agency (European Interactive Advertising Association, 2008) showed European students were dedicating a greater percentage of their time to Internet-related activities such as information gathering, online gaming and online chats as opposed to watching TV, talking on the phone or reading newspapers and books. Students were able to absorb information quickly and from multiple sources, more easily adapt to changes and had amazingly flexible minds. In addition, students were able to adopt a process rather than a content view to problem solving and searching for information.

There has been a large amount of media coverage of the supposed divide between digital natives and "digital immigrants," but in practice the distinction is less clear. Recent research by the British Library (Manchester, 2008) found that the skills and enthusiasm for Web 2.0 tools among the "Google generation" had been highly overrated, because while the students surveyed used social networks for personal activities, they were skeptical about their wider relevance, and they actually expected more traditional means of interaction to take place in the office or classroom. In addition, a study of technology usage by Kennedy et al. (2007) of first year students in Australia indicated that there is greater diversity in the use of technology by students than many commentators have suggested, so far. In particular, they found that usage of Web 2.0 technologies was quite low among their sample of so-called digital natives. Bennett, Maton, and Kervin (2008) considered that "it may be that there is as much variation within the digital native generation as between the generations" (p. 779). The authors also question the view that digital native learning styles are different from other generations as individuals have different learning preferences that may change over time. They conclude: "Young people may do things differently, but there are no grounds to consider them as alien to us. Education may be under challenge to change, but it is not clear that it is being rejected.” (Bennett et al., p. 783)

It is clear from this brief review that not all students have the aptitude for new technology characterized by the digital native label. Additionally, Browne, Hewitt, Jenkins, and Walker (2008) survey of technology-enhanced learning in universities identified lack of staff skills as the greatest inhibitor to change. The authors noted that current students were still influenced by traditional school pupil/teacher relationships and educational methods. The students also had little expectation that the university approach to learning would be any different. As the next section of the paper demonstrates, our own exploratory research with undergraduates (Harris, Warren, \& Smith, 2009) drew similar conclusions about the expectation of current students. Additionally, the research found that students struggled to see the technologies they used for social purposes actually applied in an educational or business context. One individual commented that he felt older people had an advantage in this respect - they could more easily see broader applications of the tools precisely because they had not spent their formative years "playing around" with them.

While many commentators see that the world may be changing, students and tutors may still lack digital skills, and the pressure for change from within might not be very high currently. However, even in the short term, university instructors have to accept these skills are now 
increasingly defined by employers as "basic" competencies that every educated person is expected to have. At a time when universities face criticism for declining standards and graduate unemployment is at record levels, it can be argued that producing individuals with the skills and confidence to navigate and manage the online environment is increasingly important, even within our traditional systems. Such students will stand out from the crowd by gaining access to new career opportunities, finding niche or potentially global audiences for their work, or enriching the lives of others. Those who do not display such initiative risk being marginalized or left behind right now, let alone in future if [and when] more significant structural shifts occur.

To summarize our argument so far, new technologies have raised the profile and potential of social learning, but it cannot be assumed that students, staff, or institutional structures are necessarily ready for mainstream adoption of new approaches. The next section reports on the findings of innovative experiments involving online teaching and learning within a traditional UK Business School (carried out between 2004 and 2009) in order to present recommendations for more strategic application of these principles in the university curriculum.

\section{Case Study 1}

An e-learning component of a social psychology unit was introduced as an alternative to weekly seminar classes, where progress and contributions were monitored and assessed by a tutor. Students were therefore "forced" to use technology as a learning tool as their task was to debate a psychological problem online that was part of their assessed work, accounting for $25 \%$ of the unit. Students were assigned to groups and over an 8-week period, they had to debate four topics, with 2 weeks allowed for each topic. Each student was expected to contribute to the debate, and group marks were awarded for impact and added value of their contributions. The objective was to create inter-group competition and keep students motivated. The tutor provided feedback during lecture times on how each group was performing, and provided individual feedback to each group via email every fortnight. Individuals were given marks based on three criteria: contribution in terms of academic content; evidence of reading around the topic; and, independent thought. An example of excellence was given online, from the tutor, as a guideline. A marking grid based on Poor, Average, Good and Excellent (PAGE) was developed. From annual student evaluations and comparison performance data (see Table 1) it was found that over a 3-year period, students generally achieved higher marks on this component of the unit than on the more formal components such as critiquing a paper or individual essay writing. Interestingly, differences were evidenced across the cohort as to how appropriate the students viewed this technique as a method of learning, a point that will return later in the discussion. 


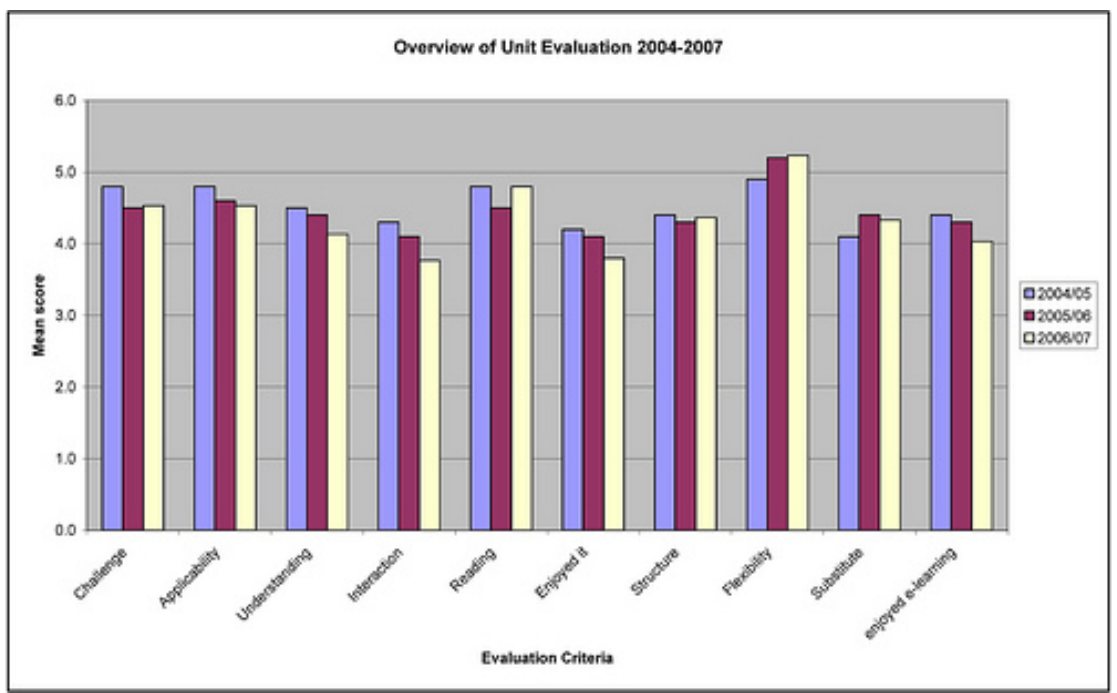

Figure 1. Evaluation of E-learning Unit for three years.

It is evident that students found the e-learning component both challenging and an appropriate substitute to the more traditional seminar. The following vignettes present a sample of students' positive and negative comments:

When everyone contributed online, we had a really good debate and being able to use the technology made life easier rather than physically going to classes. It was a great innovative way to learn, especially as it enables you to work when you want, even at 4am in the morning! (UK male)

It was fun to use technology in a useful way rather than for chatting on line or wasting time! This unit was original and made the group interact. It was fun to debate the issues and definitely made me actually do work for the course and read around the subject. (UK female)

This e-learning allows you to make a point you're really interested in very easily and makes me give ideas when I don't want to speak in group. I like it much better than presenting to class in seminar. In China, I have never done this ever, but we know technology well but we only ever learn from teacher and text book. (Chinese female)

What are noticeable through these vignettes are differences in cultural norms. For the UK participants, learning through technology presented opportunities to contribute at both sociable and unsociable hours, as well as enjoying the advantages of working from home - not having physically to attend classes, which was a positive bonus for some. Other participants found that having to proactively debate a real-world issue motivated them to read more widely around the topic area. Conversely, the Taiwanese and Chinese students found that being able to make their point after deliberate consideration, practising their writing skills and having more time to be secure in the knowledge that their contribution was the best they could achieve was a better fit for their own value systems (Chen, Mashadi, Ang, \& Harkrider, 1999).

There was more variety in negative comments, the most common being that participants missed the face-to-face contact with others and the tutors. This is a problem in virtual environments when the absence of non-verbal cues curtails the development of cohesion and trust (Jarvenpaa, Knoll, \& Leidner, 1998). Some students find that they need the physical 
presence of others in order to contribute to discussions as it creates the dynamic of social facilitation to the group, and even reduces "social loafing” in some contexts:

Still think face to face seminar classes necessary and better as communication between people is better - technology ok but we here to learn from teachers! (Chinese female) Non fluent speakers were given the opportunity to express arguments well. But I didn’t come to University to learn through technology - I'm not sure this isn't a cop out! (UK male)

\section{Case Study 2}

This example refers to teaching mainly UK/EU final year undergraduates on a Managing Innovation course from 2007-09. The unit covered a range of perspectives on innovation, including the emergence of Web 2.0 platforms, particularly in 2008-9, as usage began to increase significantly. The emphasis on Web 2.0 afforded the opportunity of using readily available software in practical discussion settings within seminar classes. During informal class interactions it became clear that while the students may have been digital natives in the sense of having been born around 1990, for the majority, it had not translated into a great deal of digital acumen. In terms of learning objectives, it was hoped that students would be able to develop the notion of innovation by creating value from readily available social media settings. In practice, however, while the students were all able to interact with digital media, they tended to interact in a fairly passive manner: Firstly, they acted as consumers of other people's material; secondly, they accessed and joined networks, but did little with them beyond making simple social connections with people they already knew (notwithstanding large friend counts); and thirdly, they communicated a lot through mobile phones, but this was largely simple texts and conversations. Yet, they still considered themselves to be digitally savvy! The distinction was noted between passive users of digital content (of course they may do this very efficiently and effectively), those who create digital content, and those who might do something really new (and not necessarily that difficult technically) such as download and play with a beta smartphone application from a firm such as Nokia. Based on this experience, the detailed categorization of users of digital media, shown below, was developed. The majority of the students fell into the "Passive" and "Creator" categories; the "Disruptor" category was something to which to aspire for all but the best students.

\section{Table 1.}

Detailed Categorization of Users of Digital Media

\begin{tabular}{|l|l|}
\hline $\begin{array}{l}\text { Passives - use what is already available but in } \\
\text { a basic and limited way. }\end{array}$ & $\begin{array}{l}\text { Register accounts on Flickr, Twitter, } \\
\text { Facebook, but little use beyond reading or } \\
\text { storage of limited amount of information. } \\
\text { Use non-smart mobile phone, talk, text, photo, } \\
\text { webcam. } \\
\text { Watch YouTube, TC, download mp3. } \\
\text { Access Digg, Delicious. } \\
\text { Play simple games, maybe online with others. }\end{array}$ \\
\hline
\end{tabular}




\begin{tabular}{|l|l|}
\hline $\begin{array}{l}\text { Creators - use what is available to create their } \\
\text { own material. }\end{array}$ & $\begin{array}{l}\text { Access and join existing networks. } \\
\text { Build collections of links on sites such as } \\
\text { Digg, Delicious. } \\
\text { Create video, picture, sound file, upload to } \\
\text { YouTube, Twitter, Flickr. } \\
\text { Use Facebook for social events largely among } \\
\text { existing friends. } \\
\text { Use smart phone, maybe download games. } \\
\text { Participate in distributed games such as World } \\
\text { of Warcraft. } \\
\text { Keep blog and update regularly. }\end{array}$ \\
\hline $\begin{array}{l}\text { Disruptors - create new networks and } \\
\text { applications. }\end{array}$ & $\begin{array}{l}\text { Use social media to develop new activities, } \\
\text { maybe with people outside their existing } \\
\text { sphere of influence. } \\
\text { Develop activities based on real-time events } \\
\text { and breaking news. } \\
\text { Main space of professional/personal identity is } \\
\text { online, rigorously maintained. } \\
\text { Build new games. } \\
\text { Look out for new applications and } \\
\text { technological developments. } \\
\text { Download applications onto smart phones and } \\
\text { extend them. }\end{array}$ \\
\hline
\end{tabular}

The benefit of developing such a categorization is that it becomes easier to assess the skill levels of staff and students, and therefore develop more finely targeted learning or development programmes that take into account their abilities (staff or students) at the outset. Further, if individuals aspire to become more digitally adept, it provides meaningful targets for them to achieve, that is, we have a means of tracking the development of ability from Passive -> Creator and Creator -> Disruptor. We may also have more realistic expectations of what can be achieved by a given combination of staff and students. This is represented in Figure 2 below. Where there are mismatches, staff, or student development may be necessary as indicated. 


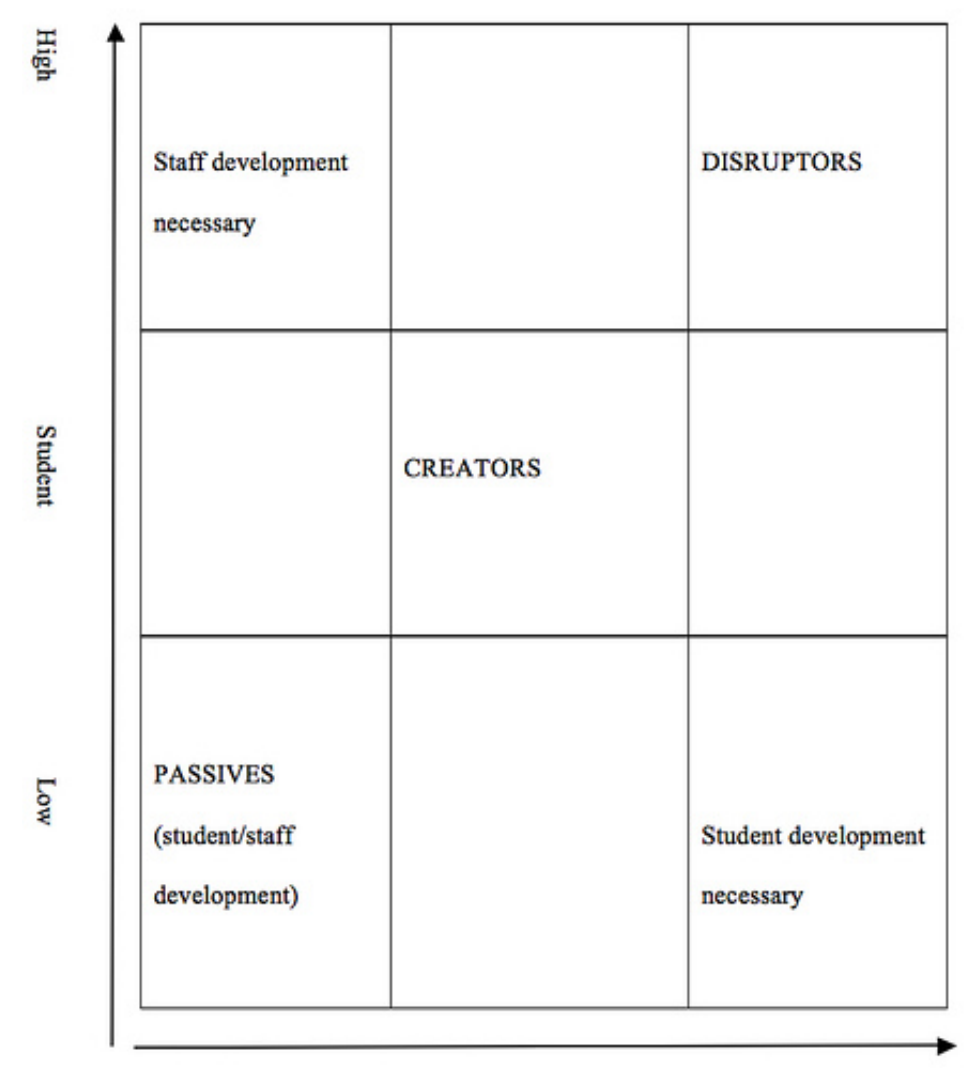

Figure 2. The development of ability from Passive -> Creator and Creator -> Disruptor.

In future, we might envisage that students in the Passive category may be less attractive to employers than the Creators. Of course, those in the Disruptive category may have more potential, but may be perceived as more risky as they challenge established ethical, social, and economic boundaries.

\section{Discussion and Recommendations}

As Bradwell (2009) notes, universities may not yet have a coherent narrative of how they will operate in the future. This serious issue needs to be addressed if we are to produce graduates that the modern business world would wish to employ. However, new educational technologies such as collaborative learning tools and online support cannot just be "bolted on" to established programmes - experience shows that a strategic approach is necessary and a significant investment in time is required in order for the approach to be effective. When "selling" the idea to staff or students, positive aspects of new technology such as demonstrating their value for collaboration and teamwork should be emphasized. Similarly, the challenges discussed earlier (such as the difficulty of evaluating diverse sources of expertise and the tendency for students to take insufficiently critical attitudes to information) should not be glossed over or ignored.

A JISC report (2009a) concludes that while advice and guidance is available to institutions, there is no blueprint for the implementation of Web 2.0 technologies, so each university is currently deciding its own path. The authors note the match between 21st-century learning skills, 21st-century employability skills and those engendered by engagement with Web 2.0 - namely communication, participation, networking and sharing. As universities are under pressure to develop their employability agendas within an environment of funding cuts and rising 
unemployment, this fortunate alignment presents an opportunity for what tends to be a small minority of change proponents among the teaching staff to ensure their ideas are taken more seriously by colleagues. In a subsequent report (JISC 2009b), the importance of staff themselves engaging in digital practice is emphasized, if they are to be credible in influencing and encouraging new learning approaches in their students.

While a structural shift in the university sector may take time, university instructors are not powerless to impact on the experience of our students and colleagues today. Some immediate solutions are discussed below.

\section{Provide structure, examples and clear guidance.}

At the operational level, facilitators of knowledge acquisition in culturally diverse environments need to enable learners to practice in different ways of constructing knowledge (Bridgland \& Blanchard, 2001). The case studies demonstrate that students have a wide range of aptitudes for educational use of technology, and they may require significant levels of structure and guidance if they are operate effectively in such environments. Creating pedagogy that meets the increasingly diverse student cohort means that university instructors have to consider a number of questions before implementing web-based technological learning. In particular:

- How are we supporting the transition towards online learning?

- Is the technology supporting the diverse learning needs?

2. Assess the learning orientation and previous experience with digital learning tools prior to experimenting with online learning.

Kickul and Kickul (2004) found that US students with a high learning goal orientation were more likely to have positive experiences when taught via e-learning methods. As noted earlier, educators need to adopt rigorous frameworks in planning programmes involving online learning techniques, and take into account some of the potential pitfalls of implementing such innovations, such as the varying levels of student skill and understanding in any one group. For example, in Case Study One, diffusion of innovations theory was adopted using the six perceived features of the technology likely to determine acceptance (Rogers, 1995). This taxonomy included simplicity, trialability, observability, relative advantage, compatibility and support which allows the educator to continuously evaluate progress and adoption rate of the innovation technique. In this case, the facilitator allowed students to trial the innovation before adopting it as part of the course. The facilitator also explained and emphasised some of the observable benefits of this method of working including sharing knowledge and flexibility of contribution times. They also designed the discussion topics around the lectures, being careful not to make the online task too complex. All of these strategic precursors helped students to construct a different mental model towards learning and so accept the programme and engage with it fully.

\section{Provide clear demonstrations of success to staff and students.}

The case studies showed that it was very motivating to current students when one of their number obtained a job in social media, thereby evidencing the demand from employers for digital skills, or if a guest lecturer left favourable comments on the students' discussion board posts. The researchers plan to offer a 'road show' to staff members over 
the next academic year which will showcase the success stories and help them to get started with their own experimentation with social media in their classes.

\section{Combine enthusiastic staff and students with less experience colleagues.}

Bringing together enthusiastic staff to teach a course in conjunction with a more sceptical colleague can allow the latter to experiment without the pressure of running a course by themselves and also benefit from the support of a mentor. The same principle can be applied in recruiting student enthusiasts to encourage less confident colleagues to participate more actively in online discussions.

\section{Don't just preach to the converted - take the debate directly to the traditionalists.}

Implicit in all the earlier recommendations is an assumption that staff and students are at least mildly receptive to trying out some aspect of online education. What about those (perhaps still a significant number) who are unaware of the possibilities, or are even downright hostile to them? If people are not engaged in social media themselves, then any online endorsement of the role of technology in education will simply pass them by. To reach out to this group, educators need a very basic version of a 'road show', delivered in a traditional setting, to even start a conversation.

Obviously, there are additional factors in the institutional context to consider in how successful they may be in developing open education contexts supported by technology platforms. Further research is needed in these dimensions:

- The type of institution: those with a bias towards design technology and creative media are likely to be more receptive than others.

- The nature of technical provision and support in the institution (open/centralised, leader or follower); one can see that it may be necessary to develop parallel systems where more creative and developmental work can take place.

- The culture and ethos of the institution (inward looking/outward facing, structures, bureaucracy, leader/follower)

- The staff development ethos (proactive or reactive)

- The type of students (entry level and type of qualification, expectations of staff particularly in early stages, exposure to opportunity at induction)

- The teaching, learning and assessment philosophy (traditional/forward thinking, collaborative/individual, student or tutor centred)

In summary, a blended approach with a flexible online/offline emphasis to account for differing student profiles, as developed in Case Study Two, is recommended. Educators cannot assume all students are digital natives responding only to the online world. European students exhibit a wide range of aptitudes for technology and experience using it, and many from parts of the Far East have had little exposure to social networking other than for entertainment purposes (China Internet Watch, 2009). Because the online model presents very different challenges to the way universities are currently structured for learning, the traditional model of education needs to change. The cases suggest that there is a place for universities in structuring and facilitating learning through embracing Web 2.0 technologies, but there is a need to establish clear educational frameworks by which curriculum design and development can best be achieved. 
Clearly, more research is needed to support the findings reported here. In doing so, a further contribution to understandings of social learning in disruptive contexts could be made. 


\section{References}

Bennett, S., Maton, K., \& Kervin, L. (2008). The 'digital natives' debate: A critical review of the evidence. British Journal of Educational Technology, 39(5), 775-786.

Bradwell, P. (2009). The edgeless university: Why higher education must embrace technology. London: Demos.

Bridgland, A., \& Blanchard, P. (2001). Flexible delivery/flexible learning...Does it make a difference? Australian \& Academic Research Libraries, 32(3). Retrieved from http://www.alia.org.au/publishing/aarl/32.3/full.text/bridgland.blanchar...

Browne, T., Hewitt, R., Jenkins, M., \& Walker, R. (2008). 2008 Survey of technology enhanced learning for higher education in the UK. Oxford, UK: UCISA.

Seeley Brown, J., \& Adler, R.P. (2008, Jan./Feb.). Minds on fire: Open education, the long tail, and learning 2.0. Educause Review, 1, 17-32.

Chen, A., Mashadi, A., Ang D., \& Harkrider, N. (1999). Cultural issues in the design of technology enhanced learning systems. British Journal of Educational Technology, 30(3), 231-245. China Internet Watch. (2009).

China social networking sites statistics 2009. Retrieved from http://www.chinainternetwatch.com/385/china-social-networking-sites-stat... summary/

Christensen, C. M., Antony, S. D., \& Roth, E.A. (2004). Seeing what's next: Using theories of innovation to predict industry change. Boston, MA: Harvard Business School Press.

David, P. A. (1991). The dynamo and the computer: An historical perspective on the modern productivity paradox. The American Economic Review, 80(2), 355-361.

European Interactive Advertising Association. (2008). TV \& radio lose out to Internet among youth audience: EIAA research reveals increasing and more sophisticated usage of the Internet among 15-24 year olds. Retrieved from http://www.eiaa.net/news/eiaa-articlesdetails.asp?lang=1\&id=66

Gualtieri, L. (2009). Five questions for George Siemens. eLearn Magazine, 3. Retrieved from http://www.elearnmag.org/subpage.cfm?section=articles\&article=78-1

Harris, L., \& Rae, A. (2010). Building a personal brand through social networking. Journal of Business Strategy, 31(2), 24-31.

Harris, L. Warren, L., \& Smith, K. (2009). Using Web 2.0 in education: Privacy and integrity in the virtual campus. Network ethics as a new challenge for higher education. Conference on Higher Education and Virtual Learning: Ethical Issues and Perspectives. Portugal: Catholic University of Lisbon.

Jarvenpaa, S.L., Knoll K., \& Leidner, D.E. (1998). Is anybody out there? Antecedents of trust in global virtual teams. Journal of Management Information Systems, 14(4), 29-64.

JISC Report. (2009a). Higher education in a Web 2 world. Retrieved from http://www.jisc.ac.uk/publications/documents/heweb2.aspx

JISC Report. (2009b). Learning literacies in digital age. Retrieved from http://www.jisc.ac.uk/publications/documents/learningliteraciesbp.aspx 
Kennedy, G., Dalgarno, B., Gray, K., Judd, T., Waycott, J., Bennett, S., Maton, K., Krause, K.L., Bishop, A., Chang, R., \& Churchward, A. (2007). The net generation are not big users of Web 2.0 technologies: Preliminary findings. ICT: Providing choices for learners and learning proceedings. Ascilite, Singapore, 2007. Retrieved from http://www.ascilite.org.au/conferences/singapore07/procs/kennedy.pdf

Kerr, B. (2007). A challenge to connectivism. Transcript of keynote speech, Online Connectivism Conference, University of Manitoba http://ltc.unimanitoba.ca/wiki/index.php?title=Kerr_Presentation

Kickul, J., \& Kickul, G., (2004). E-learning challenges and processes: Understanding the role of student self-efficacy and learning goal orientation. The International Journal of Management Education, 4(1), 29-35.

Kolb, D. A. (1984). Experiential learning: Experience as the source of learning and development. New Jersey: Prentice-Hall.

Light, R. J. (2001). Making the most of college: Students speak their minds. Cambridge, MA: Harvard University Press.

Long, P., \& Holeton, R. (2009, Mar./Apr.). Signposts of the revolution? What we talk about when we talk about learning spaces. Educause Review, 44(2), 36-49.

Manchester, P. (2008). Librarians challenge Web 2.0 youf-work myths. Retrieved from http://www.theregister.co.uk/2008/01/22/web_two_dot_zero_myths/

Prensky, M. (2001, Oct.). Digital natives, digital immigrants, do they really think differently? On the Horizon, 9(5), 1-10.

Rogers, E.M. (1995). Diffusion of innovations (4th Ed.) New York: The Free Press.

Tapscott, D. (2008). Grown up digital. New York: McGraw-Hill.

Vygotsky, L.S. (1962). Thought and language. New York: Wiley. 